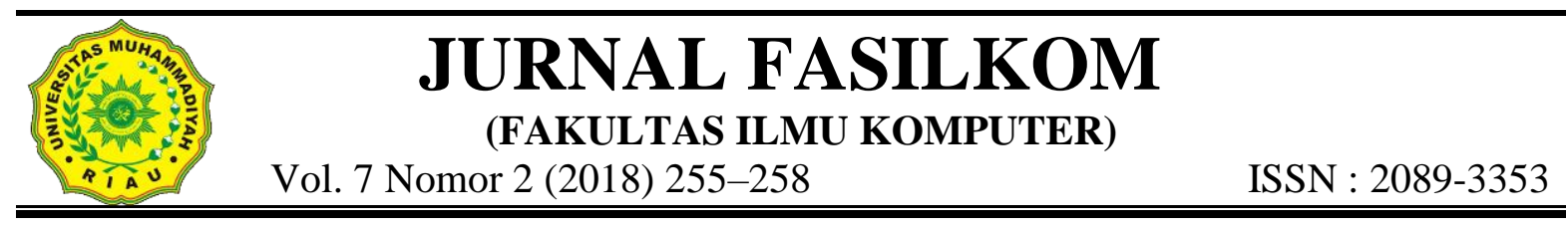

\title{
ASSOCIATION RULE MINING UNTUK MENINGKATKAN PROMOSI PRODUK ( STUDI KASUS PADA PD. XYZ )
}

\author{
Doni Winarso ${ }^{1}$, Anwar Karnaidi ${ }^{2}$ \\ ${ }^{1,2}$ Prodi Sistem Informasi Fakultas Ilmu Komputer, Universitas Muhammadiyah Riau \\ email: doniwinarso@umri.ac.id
}

\begin{abstract}
Abstrak
Analisis association rule adalah teknik data mining yang digunakan untuk menemukan aturan asosiatif antara suatu kombinasi item. penelitian ini menggunakan algoritma apriori. Dengan algoritma tersebut dilakukan pencarian frekuensi dan item barang yang paling sering muncul. hasil dari penelitian in menunjukkan bahwa algoritma apriori dapat digunakan untuk menganalisis data transaksi sehingga diketahui mana produk yang harus dipromosikan. Perhitungan metode apriori menghasilkan suatu pola pembelian yang terjadi di PD. XYZ. dengan menganalisis pola tersebut dihasilakn kesimpulan bahwa produk yang akan dipromosikan yaitu cat tembok ekonomis dan peralatan cat berupa kuas tangan dengan nilai support $11 \%$ dan confidence $75 \%$.
\end{abstract}

Kata kunci: Algoritma Apriori, Analisis Asiosiasi, Data Mining, Pemasaran,

\section{PENDAHULUAN}

Bisnis merupakan hal yang tidak bisa dihilangkan dalam kehidupan sehari-hari. Salah satu bagian dari bisnis yang cukup penting adalah pemasaran dan penjualan. Pelaku bisnis berlomba - lomba untuk mencapai hasil terbaik dari penjualan mereka dengan melihat kondisi pasar dan menganalisanya, sehingga seorang tenaga pemasar dapat melakukan pemasaran suatu produk maupun jasa yang dimilikinya dengan baik. PD. XYZ adalah sebuah perusahaan dagang yang bergerak dibidang distributor cat yang terdiri dari berbagai jenis dan merek serta peralatan, bahan dan perlengkapan dalam memenuhi kegiatan pengecatan. Umumnya konsumen dari PD. $\mathrm{XYZ}$ adalah konsumen yang bersifat end user atau pemakai langsung dari produk PD.

PD. XYZ perlu mengetahui pola konsumen dalam pemilihan dari sekian merek yang sering dibeli dan digunakan oleh konsumen dalam membantu penataan letaknya. Oleh karena itu, sebuah data penjualan sangatlah diperlukan untuk menunjang PD. XYZ dalam membaca kondisi pasar dan menentukan strategi - strategi dalam hal pemasaran sehingga produk maupun jasa yang dipunyai oleh PD. XYZ dapat terjual dan menjadi profit .Bagi sebuah bisnis yang bergerak pada bidang pemasaran seperti PD. XYZ, kesuksesan dalam pencapaian pasar menjadi tujuan utama perusahaan.

Untuk dapat bersaing dalam persaingan yang begitu ketat dalam dunia bisnis, tentunya dibutuhkan sebuah system yang dapat memproses dan menganalisa data penjualan secara cepat dan tepat.

\section{METODE PENELITIAN}

Tahapan penelitian yang digunakan pada penelitian ini dengan menggunakan metode waterfall yaitu : analisa kebutuhan, desain sistem, pengkodean, testing dan implementasi sistem dan pemeliharaan seperti gambar dan uraian dibawah ini: 


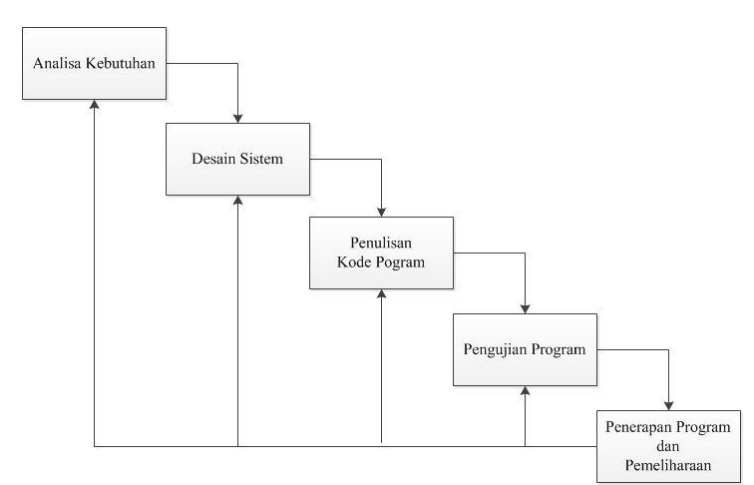

Gambar 1. Tahapan Metode Waterfall

\section{Analisa Kebutuhan}

Analisis kebutuhan adalah tahapan dimana penelitian dimulai dari menganalisa latar belakang dan masalah yang terjadi di PD. XYZ dan melakukan studi kelayakan dari pemasalahan yang akan diselesaikan oleh sistem. Dari proses tersebut maka didapatlah gambaran apa saja kebutuhan yang harus didapatkan dan juga apa yang akan dilakukan selanjutnya. Dalam hal ini, langkah-langkah tersebut yang dilakukan adalah sebagai berikut:

1. Wawancara

Yaitu suatu cara memperoleh data dengan melakukan tanya jawab langsung dengan Manager selaku pimpinan PD. XYZ.

2. Observasi

Yaitu suatu cara untuk memperoleh data dengan mengadakan pegamatan langsung terhadap objek yang akan di teliti.

3. Analisa Kebutuhan Sistem

Menganalisa kebutuhan dari sistem, serta menganalisa sistem penjualan barang yang masih manual.

\section{Desain Sistem}

Desain Sistem adalah persiapan rancang bangun implementasi yang menggambarkan bagaimana suatu sistem dibentuk yang berupa penggambaran, perencanaan dan pembuatan sketsa atau pengaturan dari beberapa elemen yang terpisah kedalam satu kesatuan yang utuh dan berfungsi, menyangkut di dalamnya konfigurasi komponen perangkat lunak dan perangkat keras dari suatu sistem.

\section{Penulisan Kode Program}

Dalam tahap ini dilakukan pemrograman. Pembuatan software dipecah menjadi modulmodul kecil yang nantinya akan digabungkan dalam tahap berikutnya. Selain itu dalam tahap ini juga dilakukan pemeriksaaan terhadap modul yang dibuat, apakah sudah memenuhi fungsi yang diinginkan atau belum selanjutnya menerjemahkan hasil proses perancangan menjadi sebuah bentuk program komputer yang dimengerti oleh mesin komputer.

\section{Pengujian Sistem}

Ujicoba software merupakan elemen yang kritis dari SQA(Software Quality Assurance) dan mempresentasikan tinjauan ulang yang menyeluruh terhadap spesifikasi, desain dan pengkodean. Ujicoba mempresentasikan ketidak normalan yang terjadi pada pengembangan software. Selama definisi awal dan fase pembangunan, pengembangan berusaha untuk membangun software dari konsep yang abstrak sampai dengan implementasi yang memungkinkan. Di tahap ini dilakukan penggabungan modul - modul yang sudah dibuat dan dilakukan pengujian ini dilakukan untuk mengetahui apakah software yang dibuat telah sesuai dengan desainnya dan masih terdapat kesalahan atau tidak.

\section{Implementasi Dan Perawatan}

Ini merupakan tahap terakhir dalam model waterfall. Software yang sudah jadi dijalankan serta dilakukan pemeliharaan. Pemeliharaan termasuk dalam memperbaiki kesalahan yang tidak ditemukan pada langkah sebelumnya. Perbaikan implementasi unit sistem dan peningkatan jasa sistem sebagai kebutuhan baru.

\section{HASIL DAN PEMBAHASAN}

Berikut data transaksi yang diambil dari data penjualan PD. XYZ yang memuat 28 transakasi untuk barang - barang yang ada :

Tabel 1. Tabel Data Penjualan

\begin{tabular}{|c|c|c|c|c|}
\hline Tgl Tran & $\begin{array}{l}\text { Id } \\
\text { Tran }\end{array}$ & Item1 & Item2 & Item3 \\
\hline 24-Okt-16 & T- 001 & $\begin{array}{l}\text { Bioton Paint } 25 \\
\mathrm{Kg}\end{array}$ & $\begin{array}{l}\text { Super Fabio } \\
\text { Paint } \\
\text { Standar } 25 \\
\text { Kg } \\
\text { Super Fabio }\end{array}$ & $\begin{array}{l}\text { Spectrum } \\
\text { NBT } 5 \mathrm{Kg}\end{array}$ \\
\hline 24-Okt-16 & T- 002 & $\begin{array}{l}\text { Spectrum TBA } 5 \\
\mathrm{Kg}\end{array}$ & $\begin{array}{l}\text { Paint } \\
\text { Standar } \quad 5 \\
\mathrm{Kg}\end{array}$ & $\begin{array}{l}\text { Plamur } \\
\text { Lippo } 4 \mathrm{Kg}\end{array}$ \\
\hline $24-O k t-16$ & T- 003 & $\begin{array}{l}\text { Super Fabio Paint } \\
\text { Standar } 25 \mathrm{Kg}\end{array}$ & $\begin{array}{ll}\text { Kuas } & \text { Roll } \\
\text { Ac } & \end{array}$ & $\begin{array}{l}\text { Kuas Euro } \\
\text { Premium 3" }\end{array}$ \\
\hline 24-Okt-16 & T- 005 & $\begin{array}{l}\text { Super Fabio Paint } \\
\text { Standar } 25 \mathrm{Kg}\end{array}$ & $\begin{array}{l}\text { Kuas Roll } \\
\text { Ac }\end{array}$ & $\begin{array}{ll}\text { Kuas } & \text { Roll } \\
\text { Mini } & \end{array}$ \\
\hline 24-Okt-16 & T- 006 & Karbit $1 \mathrm{Kg}$ & $\begin{array}{lr}\text { Top Color } \\
\text { Standar } \quad 1 \\
\text { Ltr }\end{array}$ & $\begin{array}{l}\text { Thiner } \\
\text { Dakar } 5 \text { Ltr }\end{array}$ \\
\hline 24-Okt-16 & T- 007 & $\begin{array}{l}\text { Cat Minyak SEIV } \\
1 \mathrm{Ltr}\end{array}$ & $\begin{array}{l}\text { Kuas Euro } \\
\text { Premium 2" }\end{array}$ & $\begin{array}{l}\text { Kuas Euro } \\
\text { Premium 3" }\end{array}$ \\
\hline
\end{tabular}




\begin{tabular}{|c|c|c|c|c|}
\hline 24-Okt-16 & T- 008 & Thiner HighGloss & $\begin{array}{l}\text { Cat Minyak } \\
\text { ZOOM } 1 \text { Ltr } \\
\text { Super Fabio }\end{array}$ & $\begin{array}{l}\text { Dempul } \\
\text { Alfa } 1 \mathrm{Kg}\end{array}$ \\
\hline 24-Okt-16 & T- 009 & $\begin{array}{l}\text { Super Fabio Paint } \\
\text { Spesial } 5 \mathrm{Kg}\end{array}$ & $\begin{array}{l}\text { Paint } \\
\text { Standar } 5 \\
\mathrm{Kg}\end{array}$ & $\begin{array}{l}\text { Kuas Roll } \\
\text { Ac }\end{array}$ \\
\hline 24-Okt-16 & T- 010 & $\begin{array}{l}\text { Spectrum Super } \\
\text { White } 25 \mathrm{Kg}\end{array}$ & Baki Cat & $\begin{array}{l}\text { Kuas Roll } \\
\text { Ac }\end{array}$ \\
\hline 24-Okt-16 & T- 011 & $\begin{array}{l}\text { Top Color } \\
\text { Standar } 1 \text { Ltr }\end{array}$ & $\begin{array}{l}\text { Amplas } \\
\text { Ekament }\end{array}$ & $\begin{array}{l}\text { Thiner } \\
\text { Dakar } 5 \text { Ltr }\end{array}$ \\
\hline 24-Okt-16 & T- 012 & $\begin{array}{l}\text { Thiner Cobra } \\
\text { Hijau 5 Ltr }\end{array}$ & Daimaru 1 " & Clear Lux \\
\hline 24-Okt-16 & T- 013 & Dana Gloss 1 Ltr & $\begin{array}{l}\text { Thiner } \\
\text { Dakar } 5 \text { Ltr }\end{array}$ & Clear Lux \\
\hline 24-Okt-16 & T- 014 & Clear Lux & Amplas PJL & $\begin{array}{l}\text { Thiner } \\
\text { Dakar } 1 \text { Ltr }\end{array}$ \\
\hline 24-Okt-16 & T- 015 & $\begin{array}{l}\text { Dempul Alfa } 1 \\
\mathrm{Kg}\end{array}$ & & $\begin{array}{l}\text { Thiner } \\
\text { Dakar } 5 \text { Ltr }\end{array}$ \\
\hline 24-Okt-16 & T- 016 & $\begin{array}{l}\text { Thiner Dakar } 1 \\
\text { Ltr }\end{array}$ & $\begin{array}{l}\text { Thiner } \\
\text { Cobra } \\
\text { Hitam } 1 \text { Ltr }\end{array}$ & Clear Lux \\
\hline 24-Okt-16 & T- 017 & Daimaru 1 " & $\begin{array}{l}\text { Thiner } \\
\text { Cobra } \\
\text { Hitam } 5 \text { Ltr }\end{array}$ & $\begin{array}{l}\text { Amplas } \\
\text { Niken }\end{array}$ \\
\hline 24-Okt-16 & T- 019 & $\begin{array}{l}\text { Thiner Dakar } 1 \\
\text { Ltr }\end{array}$ & $\begin{array}{l}\text { Cat Minyak } \\
\text { ZOOM } 1 \text { Ltr }\end{array}$ & $\begin{array}{l}\text { Plamur RJ } 1 \\
\text { Kg }\end{array}$ \\
\hline 24-Okt-16 & T- 020 & $\begin{array}{l}\text { Top Color } \\
\text { Standar } 1 \text { Ltr }\end{array}$ & Extra Dof & $\begin{array}{l}\text { Thiner } \\
\text { Dakar } 5 \text { Ltr }\end{array}$ \\
\hline 24-Okt-16 & T- 021 & $\begin{array}{l}\text { Top Color } \\
\text { Standar } 1 \text { Ltr }\end{array}$ & $\begin{array}{l}\text { Thiner } \\
\text { HighGloss }\end{array}$ & Daimaru $1 "$ \\
\hline 24-Okt-16 & T- 022 & $\begin{array}{l}\text { Dempul Alfa } 1 \\
\mathrm{Kg}\end{array}$ & $\begin{array}{l}\text { Amplas } \\
\text { Ekament }\end{array}$ & Clear Lux \\
\hline 24-Okt-16 & T- 023 & Thiner HighGloss & $\begin{array}{l}\text { Penta Super } \\
\text { Gloss } 1 \text { Ltr }\end{array}$ & Epoxy Dana \\
\hline 24-Okt-16 & T- 024 & $\begin{array}{l}\text { Dempul Alfa } 1 \\
\mathrm{Kg}\end{array}$ & $\begin{array}{l}\text { Thiner } \\
\text { Dakar } 1 \text { Ltr }\end{array}$ & Amplas PJL \\
\hline 24-Okt-16 & T- 025 & $\begin{array}{l}\text { Super Fabio Paint } \\
\text { Standar } 25 \mathrm{Kg}\end{array}$ & $\begin{array}{l}\text { Cat Minyak } \\
\text { SEIV } 1 \text { Ltr }\end{array}$ & $\begin{array}{l}\text { Thiner } \\
\text { Dakar } 1 \text { Ltr }\end{array}$ \\
\hline 24-Okt-16 & T- 026 & Amplas Niken & $\begin{array}{l}\text { Amplas } \\
\text { Ekament }\end{array}$ & $\begin{array}{l}\text { Thiner } \\
\text { HighGloss }\end{array}$ \\
\hline 24-Okt-16 & T- 027 & Thiner HighGloss & $\begin{array}{l}\text { Amplas } \\
\text { Ekament }\end{array}$ & Tajima 1 Ltr \\
\hline 24-Okt-16 & T- 028 & Epoxy Tajima & $\begin{array}{l}\text { Thiner } \\
\text { Dakar } 1 \text { Ltr }\end{array}$ & $\begin{array}{l}\text { Thiner } \\
\text { HighGloss }\end{array}$ \\
\hline 24-Okt-16 & T- 029 & $\begin{array}{l}\text { Dempul Alfa } 1 \\
\mathrm{Kg}\end{array}$ & $\begin{array}{l}\text { Thiner } \\
\text { HighGloss }\end{array}$ & $\begin{array}{l}\text { Kuas Euro } \\
\text { Premium } \\
1 \frac{1}{2} 2^{\prime \prime}\end{array}$ \\
\hline 24-Okt-16 & T- 030 & $\begin{array}{l}\text { Kuas Euro } \\
\text { Premium 2" }\end{array}$ & Baki Cat & $\begin{array}{l}\text { Amplas } \\
\text { Niken }\end{array}$ \\
\hline \multicolumn{3}{|c|}{$\begin{array}{l}\text { Premium } 2 " \\
\text { TOTAL TRANSAKSI }\end{array}$} & \multicolumn{2}{|r|}{ 17ки } \\
\hline
\end{tabular}

Dari data penjualan di atas akan didapatkan hubungan antar item dalam satu transaksi yang akan dihitung dan diambil jika pada transaksi lain terdapat transaksi yang mengandung kesamaan item. Dari tabel tersebut didapat beberapa hubungan item yang terbeli dan terjadi beberapa kali kemunculan di dalam tabel yang diindikasikan dengan warna yang berbeda seperti :

\section{Tabel 2. Contoh kemunculan item}

Dari data tersebut terlihat bahwa transaksi untuk pembelian produk Top Color Standar 1 Ltr maka akan membeli produk Thiner Dakar 5 Ltr dengan kemunculan 3 (tiga) kali pada tabel transaksi dengan total transaksi adalah 28 transaksi. Begitu juga dengan item barang yang lainnya, juga akan muncul sebagai hubungan item yang kemunculannya lebih dari sekali di dalam tabel transaksi dan adapun barang barang tersebut adalah sebagai berikut :

Tabel 3. Perhitungan Manual Association Rule

\begin{tabular}{|c|c|c|c|c|}
\hline $\begin{array}{c}\text { Hubunga } \\
\text { n Item }\end{array}$ & $\begin{array}{c}\text { Frek } \\
\text { uens } \\
\mathrm{i}\end{array}$ & $\begin{array}{c}\text { Frekuesi } \\
\text { Kemuncula } \\
\text { n item }\end{array}$ & Support & $\begin{array}{c}\text { Confidenc } \\
\text { e }\end{array}$ \\
\hline
\end{tabular}

\begin{tabular}{|c|c|c|c|c|}
\hline & $\begin{array}{c}\text { Item } \\
\text { set }\end{array}$ & & & \\
\hline $\begin{array}{l}\text { Jika } \\
\text { membeli } \\
\text { Super } \\
\text { Fabio } \\
\text { Paint } \\
\text { Standar } 25 \\
\text { Kg, maka } \\
\text { akan } \\
\text { mebeli } \\
\text { Kuas Roll } \\
\text { Ac }\end{array}$ & & \begin{tabular}{l} 
Frekuensi \\
kemunculan \\
Super Fabio \\
Paint \\
Standar 25 \\
Kg \\
\multicolumn{1}{l}{4} \\
\end{tabular} & $\begin{array}{c}(2 / 28) \\
\mathrm{x} 100 \% \\
= \\
7 \%\end{array}$ & $\begin{array}{r}(2 / 4 \\
) \times 100 \% \\
= \\
50 \\
\%\end{array}$ \\
\hline $\begin{array}{l}\text { Jika } \\
\text { membeli } \\
\text { Kuas Roll } \\
\text { Ac, maka } \\
\text { akan } \\
\text { membeli } \\
\text { super } \\
\text { Fabio } \\
\text { Paint } \\
\text { Standar 25 } \\
\text { Kg } \\
\end{array}$ & & 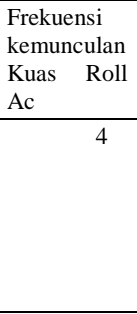 & $\begin{array}{c}(2 / 28) \\
\times 100 \% \\
= \\
7 \%\end{array}$ & $\begin{array}{r}(2 / 4 \\
) \times 100 \% \\
= \\
50 \\
\%\end{array}$ \\
\hline $\begin{array}{l}\text { Jika } \\
\text { membeli } \\
\text { Top Color } \\
\text { Standar 1 } \\
\text { Ltr, maka } \\
\text { akan } \\
\text { membeli } \\
\text { Thiner } \\
\text { Dakar } 5 \\
\text { Ltr }\end{array}$ & & $\begin{array}{l}\text { Frekuensi } \\
\text { Kemuncula } \\
\text { n Top Color } \\
\text { Standar } 1 \\
\text { Ltr } \\
\end{array}$ & $\begin{array}{r}(3 / 28) \\
\times 100 \% \\
= \\
11 \%\end{array}$ & $\begin{array}{r}(3 / 4 \\
) \times 100 \% \\
= \\
75 \\
7\end{array}$ \\
\hline $\begin{array}{l}\text { Jika } \\
\text { membeli } \\
\text { Thiner } \\
\text { Dakar 5 } \\
\text { Ltr, maka } \\
\text { akan } \\
\text { membeli } \\
\text { Top Color } \\
\text { Standar } 1 \\
\text { Ltr }\end{array}$ & & $\begin{array}{l}\text { Frekuensi } \\
\text { Kemuncula } \\
\mathrm{n} \begin{array}{c}\text { Thiner } \\
\text { Dakar 5 Ltr }\end{array} \\
\frac{5}{5}\end{array}$ & $\begin{array}{c}(3 / 28) \\
\times 100 \% \\
= \\
11 \%\end{array}$ & $\begin{array}{r}\quad(3 / 5 \\
) \times 100 \% \\
= \\
60 \\
\%\end{array}$ \\
\hline $\begin{array}{l}\text { Jika } \\
\text { membeli } \\
\text { Clear Lux, } \\
\text { maka akan } \\
\text { membeli } \\
\text { Thiner } \\
\text { Dakar } \quad 1 \\
\text { Ltr }\end{array}$ & & $\begin{array}{l}\text { Frekuensi } \\
\text { Kemuncula } \\
\text { n Clear Lux }\end{array}$ & $\begin{array}{c}(2 / 28) \\
\times 100 \% \\
= \\
7 \%\end{array}$ & $\begin{array}{r}(2 / 5 \\
) \times 100 \% \\
= \\
40 \\
\%\end{array}$ \\
\hline
\end{tabular}

Proses selanjutnya ialah menghitung support dan confidence dari data tabel transaksi di atas

\begin{tabular}{|l|l|l|l|l|}
\hline $\begin{array}{l}\text { Tgl } \\
\text { Tran }\end{array}$ & Id Tran & Item1 & Item2 & Item3 \\
\hline $\begin{array}{l}\text { 24- } \\
\text { Okt- } \\
\text { 16 }\end{array}$ & T- 006 & Karbit 1 Kg & $\begin{array}{l}\text { Top Color } \\
\text { Standar 1 Ltr }\end{array}$ & $\begin{array}{l}\text { Thiner Dakar } \\
5 \text { Ltr }\end{array}$ \\
\hline
\end{tabular}

yaitu hasilnya terlihat pada masing - masing kolom perhitungan. Adapun keterangan dari perhitungan support dan confidence adalah sebagai berikut :

- Untuk perhitungan support pembelian produk Top Color Standar 1 Ltr maka akan membeli produk Thiner Dakar 5 Ltr adalah banyak kemunculan transaksi X $100 \%$

Jumlah transaksi keseluruhan $=(3 / 28) \times 100 \%=11 \%$ 
- Untuk perhitungan confidence pembelian produk Top Color Standar 1 Ltr maka akan membeli produk Thiner Dakar 5 Ltr adalah banyak kemunculan transaksi X $100 \%$

Jumlah transaksi yang terdapat produk Top Color Standar 1 Ltr $=(3 / 4) \times 100 \%=75 \%$

Perhitungan support dan confidence di atas adalah perhitungan algoritma apriori yang merupakan perhitungan data pola frekuensi tinggi pada metode analisa asiosiasi. Selanjutnya data - data yang memiliki aturan asiosiatif akan dimunculkan menjadi sebuah data yang terkait antar item pada sistem dan akan ditampilkan juga data yang tidak termasuk ke dalam aturan asiosiasi dan akan ditampilkan pada kelompok data yang tidak terseleksi. Data yang tidak terseleksi dapat terdri dari berbagai jenis dan dapat juga berupa data yang kemunculannya banyak atau sering namun tidak ada hubungan ikatan dan tidak termasuk dalam aturan asiosiasi. Data tersebut akan dimunculkan, dan dari data ini akan diambil pengelompokan berdasarkan kategori dan dari data kategori tersebut, diambilah beberapa kategori barang yang tertinggi yang merupakan kategori barang terbanyak yang tidak masuk dalam aturan asiosiasi yang selanjutnya akan ditampilkan sebagai hasil tujuan sistem yaitu sebagai saran untuk dilakukannya promosi atau langkah pemasaran pada kategori barang tersebut, contohnya :

Rekomendasi Langkah Pemasaran :

- Lakukan Promosi Terhadap Kategori Cat Minyak

- Lakukan Promosi Terhadap Kategori Kuas Tangan

\section{Pengembangan Sistem}

Tahap ini akan dilakukan pengembangan system

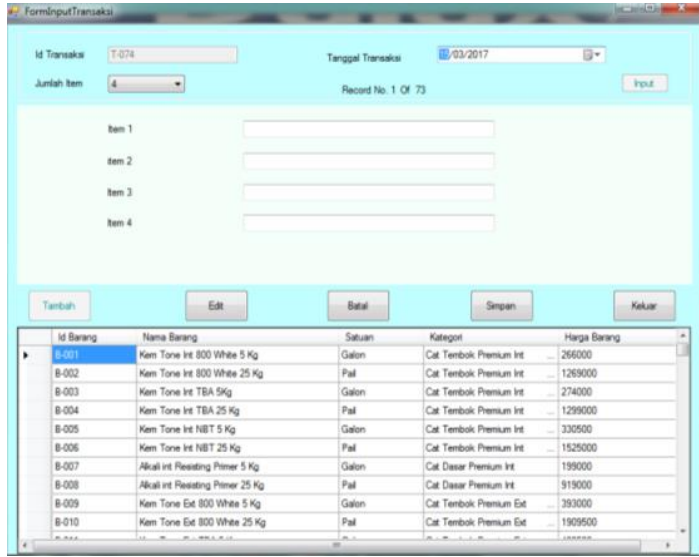

Gambar 2. Input Transaksi

Form di atas bertujuan untuk memasukan data transaksi yang terjadi di PD. XYZ yang nantinya akan diproses dalam perhitungan asiosiasinya.

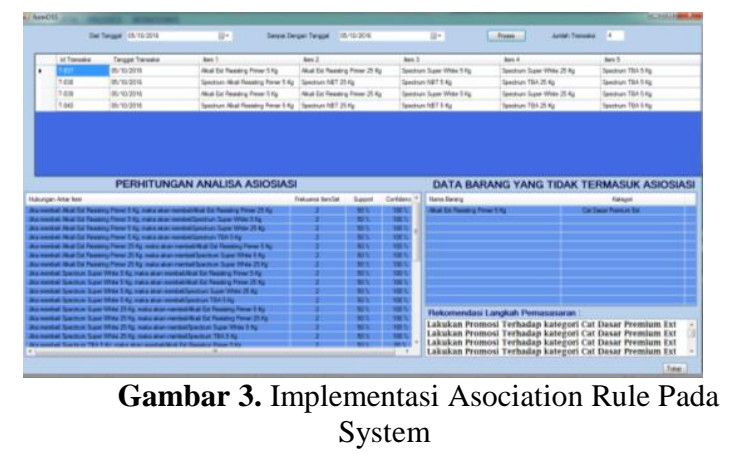

SIMPULAN DAN SARAN

\section{Simpulan}

Berdasarkan hasil penelitian diatas maka dapat disimpulkan sebagai bahwa perhitungan asisosiasi menghasilkan berupa item yang dibeli bersamaan sering muncul dalam suatu periode transaksi. Hasil Dari analisis dan perancangan yang telah dilakukan menghasilkan suatu sistem untuk membantu manajer dalam membuat keputusan terhadap penjualan yang memenuhi kebutuhan PD. XYZ yang bisa menentukan produk - produk yang akan dibuat untuk program promo. Sistem yang dibuat juga memiliki database yang bisa diakses secara cepat. Hasil akhirnya adalah memunculkan perhitungan pola frekunsi tinggi pada analisa asiosiasi yaitu support dan confidence dan juga menampilkan kategori barang yang tidak memiliki hubungan atau tidak termasuk dalam aturan asiosiasi dan menampilkan saran untuk dilakukan promo yang mana merupakan kelebihan dari penelitian terdahulu. 


\section{Saran}

Berdasarkan hasil penelitian, maka diberikan beberapa saran berkaitan dengan permasalahan yang ditemui dalam melakukan penelitian. Adapun saran-sarannya antara lain:

1. Penerapan metode lainnya memungkinkan untuk mendapatkan hasil yang lebih baik untuk pemasaran pada PD.XYZ

2. Dalam melakukan peralihan sistem yang telah ada sebaiknya dilakukan secara bertahap karena apabila dilakukan secara langsung akan mempengaruhi operasional perusahaan.

3. Sistem informasi yang dibangun hanya untuk menganalisis pemasaran sehingga perlu integrase dengan system penjualan yang telah ada di PD.XYZ.

\section{TERIMA KASIH}

Penulis mengucapkan terima kasih kepada semua pihak yang telah memberi dukungan terhadap penelitian ini.

\section{DAFTAR PUSTAKA}

[1] Bonczek, R. H., Holsapple, C.W., dan Whinston, A.B. 1981. Foundations of decision support systems. New York: Academic Press.

[2] Darmayuda, Ketut. 2009. Pemrograman Aplikasi Database dengan Microsoft Visual Basic.NET 2008. Bandung : Informatika.

[3] Erna Daniati. 2015. Algoritma Apriori Dalam Meningkatkan Pemasaran Pada Swalayan X. Kediri: Universitas Nusantara PGRI

[4] Fandy Tjioptono. 2008. Service Management mewujudkan layanan prima. Yogyakarta : Andi.

[5] Keen, P. G. W. 1980, Adaptive Design for Decision Support Systems, Data Base, Vol. 12, No. 1 dan 2.

[6] Little, J. D. C. 1970. Models and managers: the concept of a decision calculus. Management Science.

[7] M. Yusuf P. 2013. Penerapan Data Mining Association Rule MenggunakanAlgoritma Apriori Untuk Meningkatkan Penjualan Dan Memberikan Rekomendasi Pemasaran Produk Speedy. Semarang: Universitas Dian Nuswantoro.

[8] Ricky W. Griffin, Ronald J.Ebert. 2007. Bisnis Edisi Kedelapan Jilid 2. Jakarta : Erlangga.

[9] Rudi Tantra. 2012. Manajemen proyek sistem informasi. Yogyakarta : Andi.

[10] Sumadi Suryabrata, BA., Drs., Ed.S., Ph.D. 2011. Metodologi Penelitian.. Jakarta : RajaGrafindo Persada.
[11] Sutanta Edhy. 2011. Basis Data dalam Tinjauan Konseptual. Yogyakarta : Andi.

[12] Tata Sutabri, S.Kom., MM. 2004. Analisa Sistem Informasi. Yogyakarta : Andi.

[13] Turban, E., Aronson, E.J., and Liang, T.P. 2005. Decision Support System and

[14] Inteligent System (diterjemahkan oleh Prabantini, D.), edisi 7 jilid 1.Yogyakarta : Andi.

[15] Wiwit Agus T. 2014. Association Rule Mining Untuk Penentuan Rekomendasi Promosi Produk. Kudus: Universitas Muria Kudus.

[16] Nurjoko. 2015. Penerapan Data Mining Menggunakan Association Rules Untuk Mendukung Strategi Pemasaran Calon Mahasiswa Baru. Solo: Institut Bisnis dan Informatika Darmajaya. 